\title{
Low Voltage Cascode Amplifier
}

\author{
Shahab Ardalan
}

Ryerson University

Kaamran Raahemifar

Ryerson University

\section{Fei Yuan}

Ryerson University

Ardalan, S., Raahemifar, K., \& Yuan, F. (2002). Low voltage cascode amplifier. Proceedings of the 2002 45th Midwest Symposium on Circuits and Systems, 2002. MWSCAS-2002, 1, I267-I270.

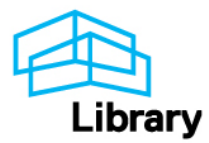




\title{
Low Voltage Cascode Amplifier
}

\author{
Shahab Ardalan, Kaamran Raahemifar, Fei Yuan, \\ \{ardalan,kraahemi,fyuan\}@ee.ryerson.ca \\ Department of Electrical and Computer Engineering \\ Ryerson Univeristy \\ Toronto, Canada, M5B 2K3
}

\begin{abstract}
A $0.8 \mathrm{~V}$ folded cascode amplifier was designed in $0.18-\mu \mathrm{m}$ standard CMOS technology. Emphasis was placed on observing the low voltage design and using current driven bulk (CDB) technique to achieve this goal. The $\mathrm{CDB}$ technique was introduced as a method for low voltage design by reducing threshold voltage. This design achieves $141 \mathrm{~dB}$ DC gain, $56 \mathrm{Mhz} 3 \mathrm{~dB}$ band width and $65 \mathrm{GHz}$ gain band width, which is the working condition of pipeline ADCs.

Index Terms - low voltage, ultra-low voltage operational amplifier, current driven bulk.
\end{abstract}

\section{INTRODUCTION}

Technology scaling is driving the supply voltages of digital circuits down to $1.2 \mathrm{~V}$ by 2004 and to $0.9 \mathrm{~V}$ by 2008 , according to the Semiconductor Industry Association's road map [1]. At the same time, the migration toward System-On-a-Chip (SoC) adds pressure on the analog circuits to follow that trend [2]. There are several approaches to ultra-low voltage supply circuit design which have recently been described; e.g., based on charge pumps [3], bulk drive [4], floating gates [5], limited commonmode range input circuits [6], [7], negative conductance [8] or CDB technique [9].

We can see the CDB technique, which is used as a method for compensating body effect [9], as means of reducing the threshold voltage in some transistors.

In this paper, we look to how CDB technique can reduce the threshold voltage in a standard CMOS process, and we use the reduced threshold voltage transistors to implement a $0.9-\mathrm{V}$ folded cascode operational amplifier with compatible input- and output levels.

Section II gives an overview of CDB technique. Section III includes the design consideration of the folded cascode operational amplifier. Simulation results and measurements are presented in Section VI and finally conclusion is made in Section V.

\section{CDB TECHNIQUE}

Current Driven Bulk (CDB) as a technique to reduce the threshold voltage of MOS transistor in standard CMOS technology is shown in [9]. Equation (1) shows the relationship between threshold-voltage and $V_{B S}$, which is called bulk bias voltage.

$V_{t h}=V_{t h 0}+\gamma\left(\sqrt{\left|2 \Phi_{F}-V_{B S}\right|}-\sqrt{2 \Phi_{F}}\right)$

where: $V_{\text {tho }}$ : Zero bias threshold voltage

$\gamma$ : Bulk effect factor

$\Phi_{F}:$ Fermi potential

The CDB technique [9] targets the absolute value of $V_{B S}$. We show, here, that technique is also applicable to transistors, which have no body effect; i.e $\mathrm{V}_{\mathrm{BS}}=0$.

Replacing this in equation (1) yields $V_{t h}=V_{t h 0}$. As this becomes evident, the bulk bias voltage does not play a significant role in threshold voltage. Our explanation for effectiveness of CDB technique is as follows. The relationship between threshold voltage and acceptor concentration $\left(\mathrm{N}_{\mathrm{A}}\right)$ in NMOS can be expressed using the following equations:

$$
\begin{aligned}
& V_{t h 0}=\Phi_{m s}+-2 \Phi_{F}-\frac{Q_{B 0}}{C_{o x}}-\frac{Q_{o x}}{C_{o x}}-\frac{Q_{1}}{C_{o x}} \\
& Q_{B 0}=\sqrt{2 q \cdot N_{A} \cdot \varepsilon_{s i} \mid-2 \Phi_{F}}
\end{aligned}
$$

Injecting a current into the bulk in NMOS would change the acceptor concentration $\left(\mathrm{N}_{\mathrm{A}}\right)$, which in turn, causes a decrease in the threshold voltage of NMOS. Same understanding is valid for PMOS and donor concentration by extracting an electron from bulk.

In reality, the turn-on phenomenon is a gradual function of the gate voltage, making it difficult 
to define $\mathrm{V}_{\mathrm{th}}$ clearly. In semiconductor physics, the $\mathrm{V}_{\text {th }}$ of an NMOS is usually defined as the gate voltage for which the interface is "as much $n$ type as the substrate is $p$-type." This definition cannot directly indicate whether the device is "on" or "off." [10] The drain current however can clearly indicate, whether the device is "on" or "off." To calculate the threshold voltage we used I-V characteristic, as follows:

$$
\begin{aligned}
& I_{D S}=\mathrm{K}\left(V_{e f f}\right)^{n}+\alpha \\
& V_{e f f}=V_{G S}-V_{t h, n}
\end{aligned}
$$

From the equations (4) and (5) one observes that Let $\mathrm{I}_{\mathrm{DSl}}, \alpha_{1}, \mathrm{~V}_{\mathrm{effl}}, \mathrm{V}_{\mathrm{GS} 1}$ and $\mathrm{V}_{\mathrm{th} 0, \mathrm{n} l}$ be the specifics of the MOS transistor without the bulk injection and $I_{\mathrm{DS} 2}, \alpha_{2}, V_{\mathrm{eff} 2}, V_{\mathrm{GS} 2}$ and $V_{\mathrm{th} 0, \mathrm{n} 2}$ be the specifics of the MOS transistor with the injection. IF $\mathrm{I}_{\mathrm{DS} 1}=\mathrm{I}_{\mathrm{DS} 2}$ and $\alpha_{1}=\alpha_{2}$ then $\mathrm{V}_{\mathrm{effl}}=\mathrm{V}_{\mathrm{eff} 2}$ from eq. (5), one can observe that

$$
\begin{aligned}
& \left(V_{G S 1}-V_{t h, n 1}\right)=\left(V_{G S 2}-V_{t h, n 2}\right) \\
& \Rightarrow \quad\left(V_{G S 1}-V_{G S 2}\right)=\left(V_{t h, n 1}-V_{t h, n 2}\right)
\end{aligned}
$$

Fig. 1: NMOS CDB transistor
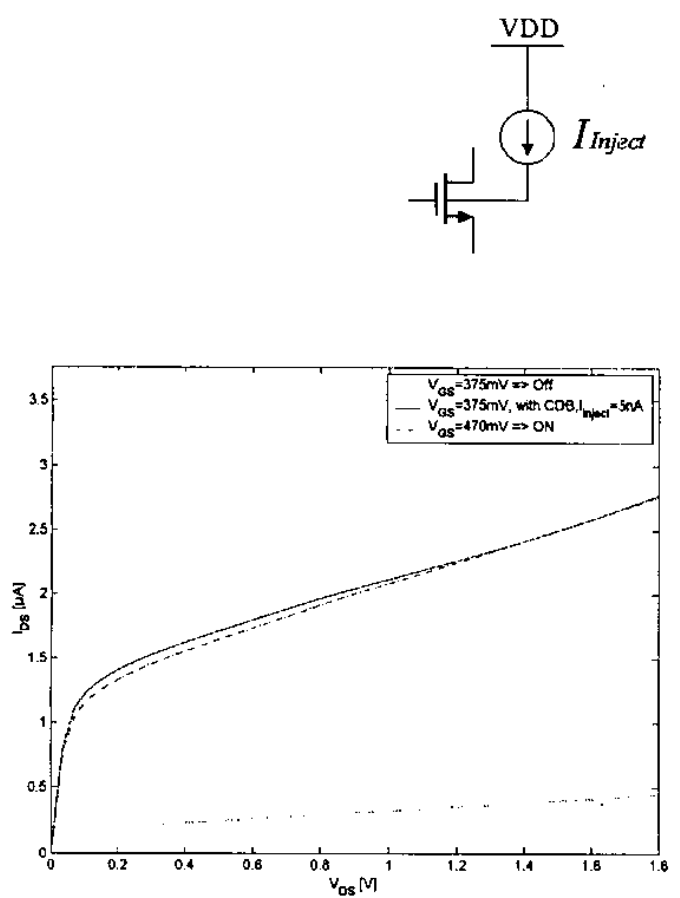

Fig.2: Transistors characteristic
Fig. 2 shows I-V characteristic for transistor with and without bulk injection. The dotted curve is for a transistor without the bulk injection and with $\mathrm{V}_{\mathrm{GS}}=375 \mathrm{mV}$. This transistor is in the offmode.

This transistor would be in on-mode when $\mathrm{V}_{\mathrm{GS}}=$ $470 \mathrm{mV}$, as shown by dash-line in Fig.2. The solid line corresponds for a transistor which has lower $\mathrm{V}_{\mathrm{GS}}=375 \mathrm{mV}$, but with bulk injection $\left(\mathrm{I}_{\text {inject }}=5 \mathrm{nA}\right)$, although the $\mathrm{V}_{\mathrm{GS}}$ of the latter transistor is smaller.

Using eq. (6) one can calculate the threshold voltage as the following example shows.

The transistor is in on-mode. However, one should appreciate the reduction in threshold voltage by approximately $100 \mathrm{mV}$, using $\mathrm{CDB}$ technique.

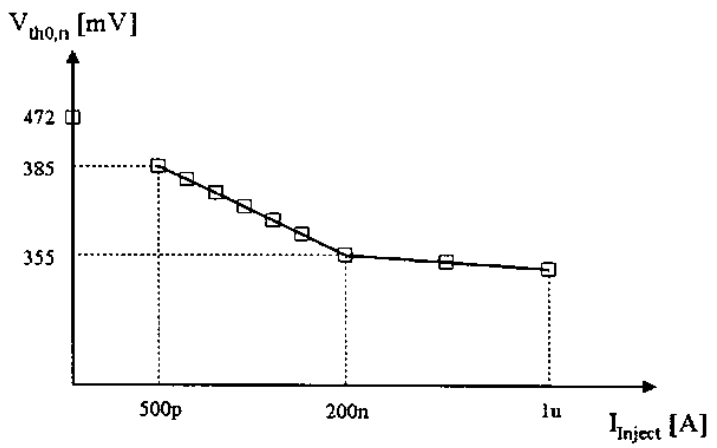

Fig.3: Effect of Inject current on threshold voltage

Fig.3 is a diagram of $\boldsymbol{V}_{t h} \boldsymbol{V}$ s. $\boldsymbol{I}_{\text {Inject. }}$ It shows the approximate range of the current injected into the bulk by which the $V_{t h}$ is considerably changed.

Here, $\mathrm{I}_{\text {inject }} \varepsilon \quad\{500 \mathrm{pA}, 200 \mathrm{nA}\}$ results in a decline in $\mathrm{V}_{\text {th } 0, \mathrm{n}}$ form $385 \mathrm{mV}$ to $355 \mathrm{mV}$.

According to [9] there are some disadvantages in CDB technique such as Output Impedance, Low Frequency Pole-Zero Pair and Slew rate.

\section{CASCODE AMPLIFIER}

The typical folded-cascode amplifier is commonly preferred for high frequency applications since the parasitic capacitance and the transconductance of the folding transistor determine the non-dominant pole of this amplifier [11].

This configuration has two advantages: 1) high voltage gain 2) large bandwidth due to less Miller effect [10]. Fig. 4 shows our amplifier, which is a standard folded cascode amplifier 


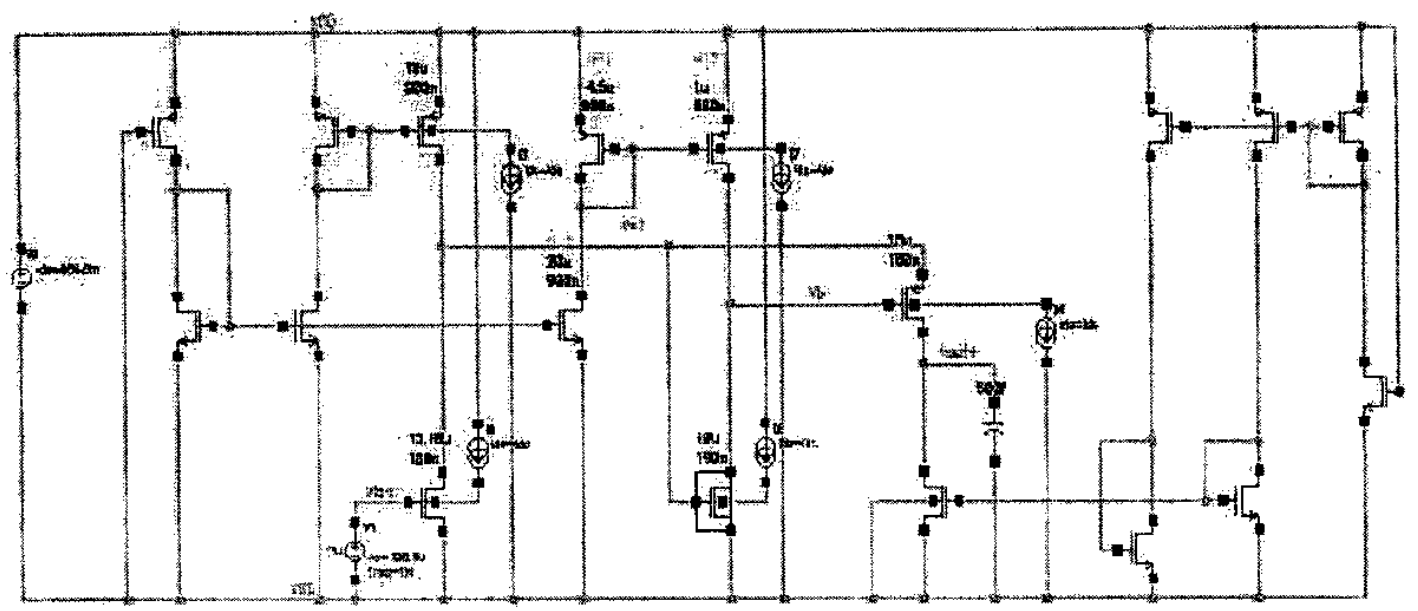

Fig.4: Schematic Diagram

with CDB transistors. Due to the concept of the CDB method, which is based on current bulk driven, we are injecting current into the circuit. In such a low voltage-design, it is an advantage to operate the cascading transistor in subthreshold, as that makes it easier to generate the bias voltages; however, it is not critical.

The other transistors should work in strong inversion mode, as good matching gives the lowest overall offset error.

The limited gain achievable in folded-cascode configuration has motivated the invention of gain-boosting techniques. These techniques are usually applied to cascade operational amplifiers to increase their gain with little degradation in speed [12],[13]. Transistor $\left(\mathrm{M}_{13}\right)$ plays a gainboosting role in our design.

\section{MEASUREMENTS}

An experimental amplifier has been simulated in a standard $0.18 \mu \mathrm{m}$ CMOS technology. Numerical results extracted from the simulations for design are shown in this section in Table 2 .

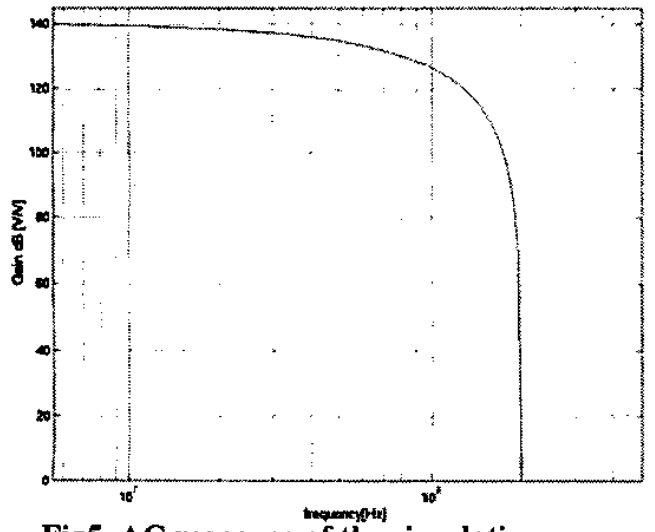

Fig5. AC response of the simulation

\begin{tabular}{|l|l|}
\hline DC Gain & $141 \mathrm{~dB}$ \\
\hline GBW & $65 \mathrm{G}$ \\
\hline 3dB freq. & $56 \mathrm{Mhz}$ \\
\hline Power & $82 \mathrm{uW}$ \\
\hline VDD & $0.8 \mathrm{~V}$ \\
\hline Output Level & $0.4 \mathrm{~V}$ \\
\hline Load & $100 \mathrm{pf}$ \\
\hline I-Inject & $10 \mathrm{nA}$ to 200nA \\
\hline
\end{tabular}

Tabel-1: Simulation result.

\section{CONCLUSION}

In this paper, we showed CDB technique as a method of reducing threshold voltage in any transistor and we designed an ultra-low voltage folded cascade, gain-boosted operational amplifier using $\mathrm{CDB}$ technique. At 0.8 volts power supply, it has a de gain of $141 \mathrm{~dB}, 50 \mathrm{MHz}$ bandwidth and $56 \mathrm{GHz}$ gain bandwidth. This design is usable for pipeline ADCs. This design was made possible by $\mathrm{CDB}$ technique as a new method of reducing threshold voltage of transistor.

\section{REFERENCES}

[1] International Technology Roadmap for Semiconductors, Semicon-ductor Industry Association, 1999.

[2] M. Waltar, K. A. I. Halonen, "1-V 9-Bit Pipelined Switched-Opamp ADC", IEEE J. Solid-State Circuits , vol. 36, pp.129-134, Jan., 2001

[3] T. A. F. Duisters and E. C. Dijkmans, "A90-dB THD rail-to-rail input opamp using a new local charge pump in CMOS,", IEEE J. SolidState Circuits, vol. 33, pp. 947-955, July 1998. 
[4] B. J. Blalock, P. E. Allen, and G. A. RinconMora, "Designing 1-V opamps using standard digital CMOS technology," IEEE Trans. Circuits Syst. II, vol. 45, pp. 769-780, July 1998.

[5] Y. Berg, D. T. Wisland, and T. S. Lande, "Ultra low-voltage/low-power digital floatinggate circuits," IEEE Trans. Circuits Syst. I, vol. 46, pp.930-936, May 1999.

[6] A. Baschirotto and R. Castello, "A 1-V 1.8$\mathrm{MHz}$ CMOSswitched-opamp SC filter with railto-rail output swing," IEEE J.Solid-State Circuits, vol. 32, pp. 1979-1986, Dec. 1997.

[7] V. Peluso, P. Vancorenland, A. M. Marques, M. S. J. Steyaert, and W.Sansen, "A 900-mV low-power A/D converter with 77-dB dynamicrange," IEEE J. Solid-State Circuits, vol. 33, pp. 1887-1897, Dec. 1998.

[8] C. Yonghua, R. L. Geiger, "Negative conductance voltage gain enhancement technique for low voltage high speed CMOS op amp design," Circuits and Systems, 2000. Proceedings of the 43rd IEEE Midwest Symposium on SC, vol. 1, pp. 502-505, 2000. [9] T. Lehmann, M. Cassia, "1-V Power Supply CMOS Cascode Amplifier", IEEE J. Solid-State Circuits, vol. 36, NO. 7, pp.1082-1086, Jul. 2001.

[10] S. M. Mallya, J. H. Nevin, "Design procedure for fully differential folded-cascode CMOS operational amplifier", IEEE J. SolidState Circuits, vol. 24, NO. 6, pp.1737-1740, Jun., 1989.

[11] B. Razavi, "Design of Analog CMOS Integrated Circuits", McGraw-Hill, 2000.

[12] B. Razavi, "Principles of Data conversion system design", IEEE Press, 1995.

[13] K. Bult, G.J.G.M. Geelen, "A fast-settling CMOS Op Amp for SC Circuits with 90-dB DC gain", ", IEEE J. Solid-State Circuits, vol. 25, pp.1379-1384, Dec. 1990. 